\title{
Pengetahuan dan Sikap Mahasiswa Fakultas Kedokteran dan Fakultas Psikologi terhadap Lansia
}

\author{
Maria Teressa, Elisabeth Rukmini \\ Medical Education Unit, Fakultas Kedokteran Universitas Katolik Indonesia Atma Jaya
}

\begin{abstract}
Abstrak
Populasi lanjut usia (lansia) di negara maju maupun negara berkembang akan meningkat dan menimbulkan masalah kesehatan. Banyaknya masalah kesehatan yang terjadi selama proses penuaan memerlukan sikap dan perhatian khusus terhadap lansia. Calon profesional yang terkait dengan bidang kesehatan perlu dipersiapkan untuk menyikapi dan memberi perhatian kepada lansia. Tujuan penelitian ini adalah untuk mendapatkan perbandingan pengetahuan dan sikap mahasiswa terhadap lansia antara mahasiswa Fakultas Kedokteran (FK) dan mahasiswa Fakultas Psikologi (FP) Unika Atma Jaya dari tanggal 1 Juli 2016 sampai 31 Desember 2016. Penelitian ini melibatkan 86 mahasiswa FK dan FP tingkat pertama, kedua, dan ketiga Unika Atma Jaya. Pengetahuan dan sikap mahasiswa terhadap lansia pada mahasiswa kedokteran dan psikologi diukur dengan alat ukur Pengetahuan dan Sikap Mahasiswa terhadap Lansia dan dibanding dengan menggunakan uji-t tidak berpasangan. Mahasiswa FK dan FP Unika Atma Jaya memiliki pengetahuan dan sikap yang tinggi terhadap lansia. Skor mahasiswa psikologi rata-rata lebih tinggi $(33,47)$ dibanding dengan mahasiswa kedokteran $(33,35)$, meskipun perbedaan ini tidak signifikan. Simpulan, tidak terdapat perbedaan pengetahuan dan sikap mahasiswa terhadap lansia antara mahasiswa kedokteran dan mahasiswa psikologi. [MKB. 2017;49(2):73-8]
\end{abstract}

Kata kunci: Lansia, mahasiswa, pengetahuan, perbandingan, sikap

\section{Medical and Psychology Students' Knowledge and Attitude toward Elderly}

\begin{abstract}
The proportion of older people is increasing worldwide, and so are the health problems. Health concerns related to aging create a growing need for health workers to provide care to elder people. Therefore, health care workers must be prepared to address and care for elderly. The aim of this study was to compare medical and psychology students' knowledge and attitude towards elderly in Atma Jaya Catholic University of Indonesia. This study was conducted from 1 July 2016 to 31 December 2016. A total of 86 of the first, second, and third year students completed a questionnaire referred to as Students' Knowledge and Attitude toward Elderly Questionnaire (SKAEQ). The medical and psychology students' knowledge and attitude was compared using independent t-test. The results showed that medical and psychology students had high knowledge and attitude towards elderly. Although the mean score of the psychology students (33.47) was higher than the medical students' (33.35), the difference was not significantly different. In conclusion, there is no difference in the knowledge and attitude towards elderly between medical and psychology students. [MKB. 2017;49(2):73-8]
\end{abstract}

Key words: Attitude, comparison, elderly, knowledge, student

Korespondensi: Maria Teressa, dr, Medical Education Unit, Fakultas Kedokteran Universitas Katolik Indonesia Atma Jaya, E-mail: tessa.180109@yahoo.com 


\section{Pendahuluan}

Berdasar atas proyeksi pada tahun 2010-2035, Indonesia sebagai salah satu negara berkembang akan mengalami ledakan jumlah penduduk lanjut usia (lansia). Data terakhir tahun 2009 menunjukkan populasi lansia di Indonesia berjumlah 20.547.541 jiwa. Diperkirakan jumlah penduduk lanjut usia di Indonesia pada tahun 2020 akan mencapai 28,8 juta jiwa atau sekitar 11\% dari total penduduk. Pada tahun 2021 usia lanjut di Indonesia diperkirakan mencapai 30,1 juta jiwa yang merupakan urutan ke-4 di dunia sesudah Cina, India, dan Amerika Serikat. ${ }^{1,2}$

Banyaknya masalah kesehatan yang terjadi selama proses penuaan karena perubahanperubahan yang dialami lansia menyebabkan diperlukan sikap dan perhatian khusus terhadap lansia. Lansia yang sakit tidak hanya menderita karena penyakit yang dideritanya, namun juga karena gangguan kesehatan jiwa seperti depresi, ansietas, demensia, atau kondisi gangguan kesehatan jiwa lainnya. Psikolog klinis, konselor, geropsikolog, psikolog rehabilitasi, maupun neuropsikolog memegang peranan yang penting dalam merawat kesehatan jiwa dan perilaku pasien lansia. Psikolog dan tenaga kesehatan lainnya berkerja sama di dalam memberikan pelayanan kesehatan yang komprehensif bagi lansia. $^{3}$

Secara langsung, pengetahuan dan sikap yang dimiliki oleh dokter dan psikolog akan berpengaruh terhadap kualitas pelayanan yang diberikan. Sikap yang benar perlu didukung dengan pengetahuan yang baik terhadap lansia. Dokter bersama dengan psikolog perlu memiliki pengetahuan dan sikap yang tepat agar dapat memberikan perawatan yang holistik dan komprehensif, serta memiliki peranan penting dalam memberikan layanan kesehatan terhadap lansia. ${ }^{4,5}$ Menentukan sistem pelayanan yang tepat harus didasari bekal tenaga kesehatan yang baik dan berkualitas. Dengan demikian, diperlukan kesadaran dari calon pengisi tenaga tersebut (mahasiswa saat ini) untuk memiliki pengetahuan dan juga sikap yang baik terhadap lansia. ${ }^{6-7}$

Penelitian yang pernah dilakukan oleh Patrick dkk. ${ }^{8}$ menunjukkan pengetahuan mahasiswa fakultas kedokteran dan teknobiologi terhadap pengetahuan dan keadaan tua kurang baik, serta tidak ada hubungan antara pengetahuan dan perspektif mahasiswa mengenai penuaan dan keadaan tua. Penelitian tersebut meneliti dari aspek pengetahuan dan perspektif mahasiswa. Di Indonesia, belum terdapat penelitian yang mengukur pengetahuan dan sikap mahasiswa FK dan FP terhadap lansia. Pada penelitian kali ini, peneliti akan mengukur pengetahuan sekaligus sikap mahasiswa dengan hipotesis penelitian terdapat perbedaan pengetahuan dan sikap mahasiswa FK dibanding dengan mahasiswa FP Unika Atma Jaya. Alat ukur yang dipergunakan adalah Pengetahuan dan Sikap Mahasiswa terhadap Lansia yang dikembangkan oleh mahasiswa Fakultas Psikologi Unika Atma Jaya yang hasilnya telah divalidasi oleh Christine dkk. $^{9}$ dan kelompoknya. Sampel yang peneliti ambil adalah mahasiswa Fakultas Kedokteran (FK) dan mahasiswa Fakultas Psikologi (FP) sebagai pembanding. Mahasiswa FK dan FP juga mempelajari psikologi perkembangan dari usia muda hingga usia tua, diharapkan terdapat fundamen data yang berarti untuk memberikan sumbangan bagi perkembangan pendidikan serta kesehatan terkait geriatri dan gerontologi.

\section{Metode}

Penelitian ini merupakan penelitian komparatif analitik yang menggunakan desain penelitian potong lintang. Penelitian dilakukan di Fakultas Kedokteran dan Fakultas Psikologi Unika Atma Jaya dari tanggal 1 Juli 2016 sampai 31 Desember 2016. Kriteria inklusi subjek penelitian adalah mahasiswa aktif FK dan FP Unika Atma Jaya dan telah melewati satu tahun masa kuliah, yaitu mahasiswa yang sudah mempelajari perkembangan manusia dari usia muda hingga tua.

Estimasi besar sampel dihitung dengan perhitungan analitik komparatif numerik tidak berpasangan dua kelompok dan sudah termasuk memperhitungkan drop out 20\%. Jumlah subjek yang diambil pengukurannya adalah 43 orang di Fakultas Kedokteran Unika Atma Jaya dan 43 orang di Fakultas Psikologi Unika Atma Jaya. Pada tiap-tiap fakultas dengan menggunakan simple random sampling, peneliti mengambil 14 mahasiswa tingkat pertama, 15 mahasiwa tingkat kedua, dan 14 mahasiswa tingkat ketiga.

Peneliti mempergunakan kuesioner yang dibuat oleh mahasiwa FP Unika Atma Jaya, yaitu Christine dkk. ${ }^{9}$ berjudul "Pengetahuan dan Sikap Mahasiswaterhadap Lansia." Kuesioneriniadalah hasil karya mahasiswa yang dibimbing oleh seorang dosen psikometri sebagai bagian dari tugas mata kuliah lanjut psikometri pembuatan alat ukur. Saat ini belum ada instrumen penelitian yang mengukur pengetahuan dan juga sikap seseorang terhadap lansia dengan 
menggunakan alat ukur yang sama. Selain itu, kelebihan instrumen penelitian ini adalah kuesioner ini sudah diadaptasi terhadap budaya masyarakat Indonesia dan telah diuji validitas dan reliabilitasnya. Penyusunan alat ukur ini telah disertai dengan validasi alat dengan testretest untuk surface validity, dan expert validity melalui wawancara terhadap pakar lansia di FKUAJ dan FPUAJ; sementara reliabilitas dalam tiga kali percobaan menghasilkan perhitungan Cronbach alpha $>0,85 .^{9}$

Jenis kuesioner yang dipergunakan adalah situational judgment test (SJT). SJT merupakan tipe tes psikometris yang memberikan skenario situasi nyata dan meminta responsden untuk mengidentifikasi respons yang paling sesuai atau meminta responsden memberikan urutan pada pilihan respons berdasar atas apa yang menurut mereka paling efektif serta akan mereka lakukan di kehidupan nyata. Skenario kuesioner ini berupa soal cerita tentang kondisi kehidupan sehari-hari yang dialami oleh lansia dan pertanyaan mengenai sikap terhadap skenario tersebut. Pada awalnya disusun 25 skenario dalam bentuk SJT. Tahap berikutnya adalah langkah expert judgment untuk menilai skenario dapat mengukur konstruk yang hendak diukur atau tidak. Ada tiga pakar yang terlibat dalam penilaian ini, dua orang dari FKUAJ dan satu orang dari FPUAJ. Setelah mengalami revisi skenario berdasar atas masukan para pakar, kuesioner kemudian diedarkan kepada kelompok percobaan yang merupakan mahasiswa FKUAJ dan FPUAJ, tetapi yang bukan target dari penelitian ini. Uji surface validity dari sisi keterpahaman berlangsung baik. Setelah perhitungan statistik, 9 soal gugur karena tidak memberikan makna. Total kuesioner berisi 16 pertanyaan. Tes ulang dari kuesioner akhir juga menghasilkan Cronbach alpha yang baik $(>0,85)$. Dengan demikian, alat ukur tersebut diputuskan untuk digunakan dalam penelitian ini.

Skenario yang digunakan misalnya seperti dalam contoh di bawah ini:

Kakek Budi beberapa hari ini sering mengalami sakit di dada kirinya, namun sangat enggan memeriksakan kesehatannya ke dokter. Kegiatan sehari-hari kakek tersebut menjadi terganggu karena gangguan fisik yang dialaminya ini. Anda dan keluarga sudah membujuk kakek untuk memeriksakan dirinya agar mendapat perawatan, namun kakek tetap tidak mau. Bagaimana respons Anda?

Tetap mengajak kakek memeriksakan diri sampai kakek mau. (skor: 3)

Memberikan suplemen atau vitamin kepada kakek sebagai pengganti konsultasi dengan dokter. (skor: 2)

Memberikan kakek alternatif lain seperti minum ramuan herbal selama kakek tidak mau diperiksakan ke dokter. (skor: 0)

Memberikan asupan gizi yang lebih kepada kakek sehingga kakek tidak perlu memeriksakan dirinya. (skor: 1)

Nenek Neli yang berusia 65 tahun sangat suka memasak. Suatu kali iaingin mengambil bumbu dapur yang terletak di lemari bagian atas. Nenek Neli harus naik ke kursi agar dapat mengambil bumbu dapur tersebut. Ketika anaknya melihat kejadian tersebut, nenek Neli sudah naik ke kursi dan sedang menggapai lemari bagian atas. Bagaimana sikap Anda terhadap kejadian tersebut?

Menjaga kursi dan nenek agar tetap stabil. (skor: 3)

Memarahi nenek dan meminta nenek untuk turun. (skor: 1)

Membiarkan saja dan yakin bahwa nenek akan baik-baik saja. (skor: 0)

Mengambilkan barang yang diinginkan nenek. (skor: 2)

Pada kasus nomor 1 , sikap yang hendak diukur adalah konsistensi atas dasar pengetahuan kedokteran responsden bahwa pemeriksaan dada kiri sangat krusial. Oleh karena itu, pilihan A memberikan skor tertinggi. Pada skenario kedua sikap yang hendak dinilai adalah penghargaan terhadap kemerdekaan pemilik tubuh sehingga memberikan kebebasan kepada lansia penting diiringi dengan pengetahuan bahwa kemungkinan lansia jatuh akan terjadi dan rentan. Oleh karena itu, skenario kedua memberikan peluang untuk bersikap menjaga kestabilan kursi sehingga nenek tidak jatuh.

Dalam kuesioner, terdapat 16 skenario dan pada setiap skenario, mahasiswa diminta untuk memilih satu jawaban yang menurutnya paling tepat sesuai dengan pengetahuan yang dimiliki. Tidak ada jawaban benar atau salah karena jawaban yang dipilih merupakan sikap yang diperlihatkan oleh responsden. Setiap pilihan jawaban mempunyai rentang nilai 0-3. Nilai maksimum dari total jawaban yang dipilih adalah 48 dan nilai minimum adalah 0 . Seseorang dinyatakan memiliki pengetahuan dan sikap yang rendah terhadap lansia jika hasil pengukuran total skor jawaban yang dipilih berada di rentang nilai $0-29$, sedangkan di rentang nilai 30-48 menunjukkan pengetahuan dan sikap yang tinggi terhadap lansia. 
Baik kelompok FK maupun FP, uji normalitas menunjukkan nilai $p>0,05$, yaitu distribusi data normal. Dengan demikian, data numerik mengenai perbandingan pengetahuan dan sikap mahasiswa mengenai lansia pada mahasiswa FK dan FP Unika Atma Jaya diuji dengan uji-t tidak berpasangan.

Penelitian ini telah memperoleh persetujuan dari Komisi Etik Fakultas Kedokteran Unika Atma Jaya. Seluruh subjek penelitian telah menyatakan persetujuan untuk menjadi responsden dalam penelitian ini.

\section{Hasil}

Responden pada penelitian ini berasal dari Fakultas Kedokteran Unika Atma Jaya sebanyak 12 mahasiswa pria dan 31 mahasiswa wanita dengan total sebanyak 43 mahasiswa. Kelompok pembanding diambil dari Fakultas Psikologi Unika Atma Jaya sebanyak 10 mahasiswa pria dan 33 mahasiswa wanita dengan total 43 mahasiswa (Tabel 1).

Hasil pengukuran pengetahuan dan sikap mahasiswa terhadap lansia pada mahasiswa FK dan FP berada pada rentang nilai 30-48, dengan demikian mahasiswa FK maupun FP Unika Atma Jaya memiliki pengetahuan dan sikap yang tinggi terhadap lansia.

Perbandingan antara pengetahuan dan sikap mahasiswa terhadap lansia pada mahasiswa FK dan FP diuji memakai uji-t tidak berpasangan (Tabel 2). Hasil menunjukkan nilai $p=0,892$. Nilai $p>0,05$ yang berarti tidak terdapat perbedaan yang bermakna pengetahuan dan sikap antara mahasiswa FK dan mahasiswa FP Unika Atma Jaya.

\section{Pembahasan}

Berdasar atas hasil penelitian, pengetahuan dan sikap mahasiswa FK terhadap lansia lebih rendah dibanding dengan mahasiswa FP, meskipun perbedaan ini tidak signifikan. Hal ini berbeda dengan hipotesis awal yang menyatakan bahwa terdapat perbedaan antara kedua kelompok tersebut.

Pada awalnya, peneliti menduga bahwa pengetahuan dan sikap mahasiswa FK lebih tinggi dibanding dengan mahasiswa FP. Alasan dugaan ini adalah karena mahasiswa FK telah mempelajari lansia secara medis sehingga mahasiswa FK semestinya lebih paham mengenai sikap tepat terhadap lansia dalam skenario kuesioner tersebut. Dugaan awal peneliti didukung oleh penelitian lain yang menggunakan Kogan's Attitude toward Old People (KAOP)untuk menilai sikap mahasiswa kedokteran terhadap lansia. Hasil memperlihatkan sikap mahasiswa kedokteran lebih positif. Sikap mahasiswa yang lebih tinggi dipengaruhi oleh beberapa faktor seperti jenis kelamin, situasi ekonomi keluarga, dan keinginan untuk bekerja di sektor geriatri. ${ }^{10}$ Namun, sebenarnya asumsi ini tidak berlaku bagi semua penelitian yang mengukur pengetahuan dan sikap mahasiswa terhadap lansia. Penelitian lain yang menggunakan Facts about Aging Quiz oleh Palmore (FAQ) dan Aging Semantic Differential Scale (ASD) terhadap mahasiswa kedokteran menjelaskan tidak ada korelasi signifikan antara jenis kelamin dan situasi tempat tinggal terhadap pengetahuan, namun pengetahuan yang tinggi cenderung menunjukkan sikap yang positif terhadap lansia. ${ }^{11}$

Nilai pengetahuan dan sikap mahasiswa FP yang lebih tinggi disebabkan oleh sikap mahasiswa tidak hanya terbentuk pengetahuan dasar yang didapatkan dari masa kuliah, namun juga karena pengalaman pribadi berinteraksi dengan lansia. Di Unika Atma Jaya, mahasiswa FK mempelajari mengenai anatomi dan fisiologi lansia dalam blok Siklus Kehidupan dan Penuaan Alamiah (SKPA), sedangkan penurunan fungsi fisiologi dan penyakit yang banyak dialami oleh lansia diintegrasikan dengan blok-blok lainnya. Pengetahuan yang didapatkan ketika kuliah ini tidak menjamin bahwa mahasiswa FK memiliki pengetahuan dan sikap yang lebih baik dibanding dengan mahasiswa lain. Hasil penelitian ini serupa dengan sebuah penelitian di Spanyol. Penelitian tersebut menggunakan ASD dan menunjukkan bahwa kelompok mahasiswa yang memiliki sikap lebih positif terhadap lansia secara berurutan dari yang paling tinggi adalah mahasiswa fakultas psikologi, sosial, terapi okupasional, kedokteran gigi, fisioterapi, kedokteran, dan keperawatan. Dari penelitian tersebut, sikap mahasiswa FP yang lebih positif terhadap lansia dapat disebabkan oleh mahasiswa FP memiliki kesadaran sosial lebih tinggi terhadap lansia. Mahasiswa FK memiliki sikap yang lebih negatif, sedangkan seharusnya mahasiswa FK memiliki kesempatan lebih besar untuk berinteraksi dengan lansia, misalnya pada kegiatan kunjungan ke elder care. ${ }^{12}$

Penelitian lain terhadap mahasiswa FP dan ilmu sains lainnya yang dinilai dengan FAQ, Anxiety about Aging Scale, dan Fraboni Scale on Ageism menunjukkan tidak ada perbedaan 
signifikan antara pengetahuan dan kecemasan berdasar atas jenis kelamin. Meskipun demikian, pengetahuan dan interaksi dengan lansia yang secara tidak langsung disebabkan oleh rasa cemas memengaruhi sikap partisipan terhadap lansia. ${ }^{13}$

Mahasiswa FK seharusnya memiliki nilai pengetahuan dan juga sikap terhadap lansia yang lebih tinggi dibanding dengan mahasiswa FP oleh karena mahasiswa FK mempelajari lebih mendetail teori mengenai penurunan fungsi serta masalah kesehatan pada lansia. Mahasiswa FK lebih mempelajari aspek medis mengenai lansia, sedangkan pada mahasiswa FP lebih banyak mempelajari aspek sosial pada lansia. Dari beberapa penelitian sebelumnya, aspek pengetahuan dan sikap terhadap lansia dapat dipengaruhi oleh pendidikan gerontologi serta interaksi dan pengalaman klinis dengan lansia. ${ }^{12,14-16}$ Pendidikan mengenai lansia dapat berasal dari modul atau kuliah yang ada di kurikulum fakultas. Dari hasil penelitian ini, dapat diperkirakan Unika Atma Jaya belum menekankan secara holistik aspek geriatri dan gerontologi pada kurikulum di fakultas kedokteran.

Pemahaman akan lansia secara langsung dipengaruhi oleh interaksi dengan lansia. Mahasiswa FK perlu memiliki lebih dari sekedar pengetahuan untuk membentuk sikap dan perspektif baik terhadap lansia. Kurikulum di fakultas kedokteran perlu lebih menekankan komponen yang menekankan pada kehidupan lansia dan meluruskan konsep yang salah mengenai penuaan. Sebuah studi kohort telah menunjukkan bahwa kurikulum interprofesional kedokteran geriatri meningkatkan pengetahuan dan sikap mahasiswa terhadap lansia. ${ }^{17}$ Pada penelitian lainnya, ${ }^{18}$ hasil post-test setelah mengikuti aktivitas service learning selama 10 minggu menunjukkan peningkatan signifikan pengetahuan dan juga penurunan sikap negatif terhadap lansia. ${ }^{18}$

Sikap yang negatif terhadap lansia dapat menyebabkan minat yang rendah mahasiswa FK maupun kesehatan untuk bekerja di sektor lansia. Hal ini menjadi perhatian besar karena jumlah lansia yang terus meningkat dari tahun ke tahun perlu diimbangi dengan jumlah tenaga kesehatan yang sesuai. Lansia kini menempati proporsi terbesar yang menggunakan pelayanan kesehatan sehingga kebutuhan jumlah tenaga kesehatan di sektor lansia perlu memadai. Teknik pembelajaran secara aktif seperti permainan simulasi dan role play mengenai masalah fungsional yang dialami lansia dapat memberikan pengalaman terhadap mahasiswa akan kehidupan lansia. ${ }^{19}$

Penelitian ini juga mememiliki keterbatasan. Alat ukur dalam penelitian ini dibuat sesuai dengan budaya dan juga kebiasaan masyarakat Indonesia sehingga hanya berlaku untuk dapat menilai mahasiswa Indonesia. Sampai sekarang, kuesioner ini belum digunakan oleh para peneliti lain. Peneliti hanya dapat membandingkan hasil yang peneliti dapatkan dengan hasil penelitian serupa yang menggunakan alat tes lain.

Penelitian ini merupakan penelitian analitik sehingga jumlah sampel yang dibutuhkan tidak sebanyak penelitian deskriptif. Peneliti beranggapan apabila jumlah sampelnya dapat ditambah, hasil yang diperoleh pun akan lebih merepresentasikan pengetahuan dan juga sikap responden.

Simpulan, mahasiswa FK dan FP memiliki pengetahuan dan sikap yang tinggi terhadap lansia.

\section{Daftar Pustaka}

1. Kementerian Kesehatan RI. Gambaran kesehatan lanjut usia di Indonesia. Jakarta: Kemenkes RI; 2011.

2. Kementerian Kesehatan RI. Triple burden ancam lansia [Internet].[diunduh 28 Maret 2015]. Tersedia dari: http://www.depkes. go.id/article/print/13100008/tripleburden-ancam-lansia.html.

3. Psychology and aging: psychologists make a significant contribution [Internet]. [diunduh 6 Februari 2016]. Tersedia dari: http:// www.apa.org/pi/aging/resources/guides/ psychology-and-aging.aspx.

4. Koh LC. Student attitudes and educational support in caring for older people--a review of literature. Nurse Educ Pract. 2012;12(1):16-20.

5. Celik SS, Kapucu S, Tuna Z, Akkus Y. Views and attitudes of nursing students towards ageing and older patients. Aust J Adv Nurs Online. 2010;27(4):24-30.

6. Wang CC, Liao WC, Kao MC, Chen YJ, Lee MC, Lee MF, dkk. Taiwanese medical and nursing student interest levels in and attitudes towards geriatrics. Ann Acad Med Singapore. 2009;38(3):230-6.

7. Chua MPW, Tan CH, Merchant R, Soiza RL. Attitudes of first-year medical students in Singapore towards older people and willingness to consider a career in geriatric medicine. Ann Acad Med Singapore. 2008;37(11):947-51. 
8. Patrick, Arieselia Z, Rukmini E. Pengetahuan dan perspektif mahasiswa tentang penuaan dan keadaan tua. MKB. 2014;46(4):209-15.

9. Christine Y, Amanda G, Mangesti A. Penyusunan alat ukur pengetahuan dan sikap mahasiswa terhadap lansia, Laporan Hasil Kerja Psikometri. 2014. (unpublished paper)

10. Ayoğlu FN, Kulakçı H, Ayyıldız TK, Aslan GK, Veren F. Attitudes of Turkish nursing and medical students toward elderly people. J Transcult Nurs. 2014;25(3);241-8.

11. Wiese CH, Fragemann K, Keil PC, Bundscherer AC, Lindenberg $\mathrm{N}$, Lassen CL, dkk. Geriatrics in medical students' curricula: questionnaire-based analysis. BMC Res Notes. 2014;7(1):1-10.

12. Zambrini DAB, Moraru M, Hanna M, Kalache A, Nuñez JFM. Attitudes toward the elderly among students of health care related studies at the University of Salamanca Spain. J Contin Educ Health Prof. 2008;28(2):8690.

13. Allan LJ, Johnson JA. Undergraduate attitudes toward the elderly: the role of knowledge, contact and aging anxiety. Educ Gerontol. 2008;35(1):1-14.
14. Gonçalves DC. From loving grandma to working with older adults: promoting positive attitudes towards aging. Educ Gerontol. 2009;35(3):202-25.

15. Cheong SK, Wong TY, Koh GCH. Attitudes towards the elderly among Singapore medical students. Ann Acad Med Singapore. 2009;38(10):857-61.

16. Liu Z. Survey of attitude towards and understanding of the elderly amongst Chinese undergraduate medical students. Asian Biomed. 2014;8(5):615-22.

17. Koh GCH, Ling CLH, Ma BHM, Chen C, Lim WS, Scherer SC, dkk. Effect of a new longitudinal interprofessional geriatric medicine educational track on knowledge and attitude of medical students: a controlled cohort study. J Am Geriatr Soc. 2015;63(3):558-64.

18. Leung AYM, Chan SSC, Kwan CW, Cheung MKT, Leung SSK, Fong DYT. Service learning in medical and nursing training: a randomized controlled trial. Adv Health Sci Educ. 2011;17(4):529-45.

19. Douglass C, Henry BW, Kostiwa IM. An aging game simulation activity for allied healthstudents. Educ Gerontol. 2008;34(2):124-35. 